\title{
Carotid artery cannulation in acute aortic dissection with malperfusion
}

\author{
Paul P. Urbanski, MD, PhD, Bad Neustadt, Germany
}

$\mathrm{M}$ alperfusion has been identified in many series as an independent risk factor for increased perioperative mortality and morbidity in acute aortic dissection. Different approaches for surgical intervention and especially for arterial cannulation are still being discussed to improve surgical outcome in this patient group. ${ }^{1-3}$

We report 2 patients with acute aortic dissection having signs of malperfusion in whom proximal aortic repair with carotid artery cannulation led to excellent surgical outcome.

\section{Clinical Summary}

CASE 1. A 70-year-old man with a history of hypertension, coronary heart disease, and aortic valve defect experienced sudden thoracic pain 4 years after coronary artery bypass grafting and aortic valve replacement. Shortly after admission to our institution, he was lethargic and not responsive. A computed tomogram (CT) angiograph of the aorta showed an extended acute aortic dissection involving supra-aortic branches and iliac arteries. The innominate artery and both carotid arteries showed severe compression of the true lumen by the false lumen (Figure 1).

To avoid insufficient cerebral perfusion through the narrowed true lumen during cardiopulmonary bypass (CPB), we prepared the left common carotid artery through a separate incision on the neck and cannulated it with a $10-\mathrm{mm}$ Dacron side graft. In turn, for sufficient perfusion of the rest of the body, a second arterial line was installed in the right femoral artery, which was dissection free. Both arterial lines were connected with a Y-shaped tube for arterial return from one pump. Distal aortic repair (hemiarch replacement) was performed during circulatory arrest in moderate hypothermia $\left(28.0^{\circ} \mathrm{C}\right)$ by using unilateral cerebral perfusion through the cannulated carotid artery with a flow of about $0.8 \mathrm{~L} / \mathrm{min}$ for brain protection.

CASE 2. A 62-year-old man with a history of coronary heart disease and previous multiple coronary catheter interventions experienced sudden pain in the abdomen and lower extremities 4 days after the last coronary angioplasty. Both legs became pale and pulseless. A CT-angiograph showed an extended aortic dissection with massive compression of the true lumen by the false lumen in

\footnotetext{
From the Department of Cardiovascular Surgery, Cardiovascular Clinic Bad Neustadt, Bad Neustadt, Germany.

Received for publication Jan 13, 2006; revisions received Jan 26, 2006; accepted for publication Feb 6, 2006.

Address for reprints: Paul Urbanski, MD, PhD, Herz- und Gefaess-Klinik, Salzburger Leite 1, 97616 Bad Neustadt, Germany (E-mail: p.urbanski@ kardiochirurg.de).

J Thorac Cardiovasc Surg 2006;131:1398-9

$0022-5223 / \$ 32.00$

Copyright @ 2006 by The American Association for Thoracic Surgery doi:10.1016/j.jtcvs.2006.02.005
}

the abdominal aorta and the resulting malperfusion of the abdominal organs and lower extremities (Figure 2). Intrathoracic side-graft cannulation of the left common carotid artery allowed an antegrade perfusion of the true lumen during CPB. Aortic arch replacement

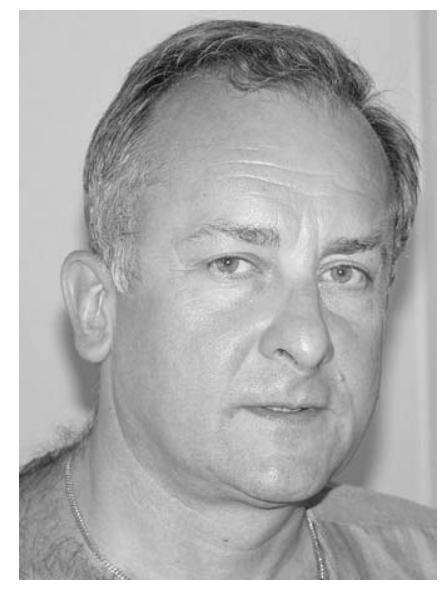

Dr Urbanski with reimplantation of the innominate artery and the left common carotid artery was performed during circulatory arrest in moderate hypothermia $\left(29.0^{\circ} \mathrm{C}\right)$, with brain protection achieved by using unilateral cerebral perfusion through the left carotid artery with a flow of about $1.0 \mathrm{~L} / \mathrm{min}$. After reinstitution of CPB, valvesparing ascending aortic replacement and coronary artery bypass grafting completed the procedure.

In both cases the postoperative course was uneventful. The postoperative CT imaging showed a complete recession of the false lumen in the supra-aortic branches in case 1 and a nearly complete recession of the false lumen in the abdominal aorta in case 2 (Figures 1 and 2). Currently, about 3 years after the operation, both patients are well and have no clinical symptoms.

\section{Discussion}

During surgical repair of acute aortic dissection with femoral cannulation, a clamping of the aorta before completion of the distal repair should be avoided to eliminate the risk of false lumen perfusion. ${ }^{4}$ Consequently, a cannulation of the femoral artery is always associated with the necessity of circulatory arrest in deep hypothermia. Even though selective cerebral perfusion for brain protection is used, the cerebral flow has to be interrupted for the placement of the perfusion cannulas in the supra-aortic vessels.

Cannulation of the supra-aortic vessels for $\mathrm{CPB}$, of which the cannulation of the axillary artery is the most common, offers the advantage of antegrade perfusion of the aorta. ${ }^{1}$ In addition, performing cerebral perfusion during circulatory arrest is facilitated because just one more vessel must be cannulated for the completion of bilateral brain perfusion. However, this additional manipulation can be avoided by using unilateral cerebral perfusion.

The cannulation of the carotid artery for $\mathrm{CPB}^{5}$ offers some advantages, which are especially apparent in an acute aortic dissection. Surgical access is very easy and quick and therefore suitable for emergencies. Furthermore, in cases with compression of the true lumen in both of the carotid arteries, cannulation of one of them, as presented in case 1, ensures at least unilateral unrestricted cerebral perfusion during CPB. During circulatory arrest, unilateral cerebral perfusion is very easy to manage simply by reducing the flow in the arterial line after the clamping of all arch arteries. 

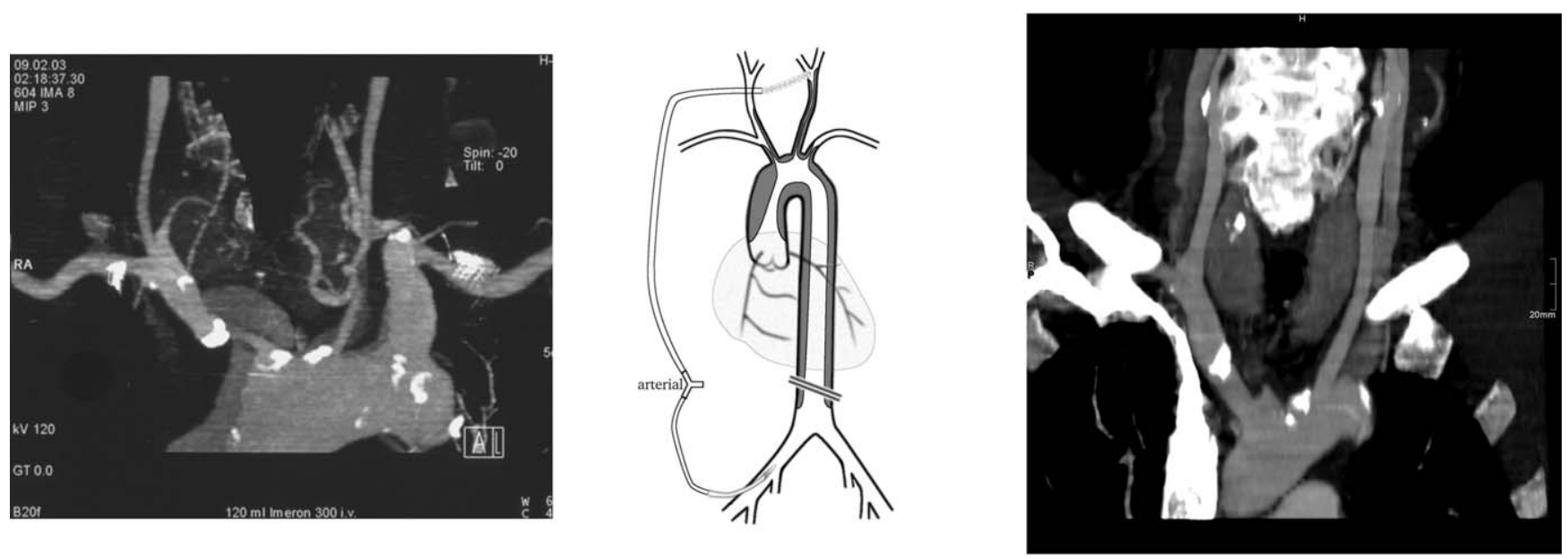

Figure 1. Left, Preoperative computed tomogram-angiograph showing aortic dissection involving the aortic arch and supra-aortic vessels with massive compression of the true lumen by the false lumen in the innominate artery and both common carotid arteries. Middle, Schematic illustration of aortic dissection and arterial return installation in the left common carotid artery and the right femoral artery through a Y-shaped line. Right, Postoperative computed tomogram-angiograph showing complete extension of the true lumen in the innominate artery and both carotid arteries.
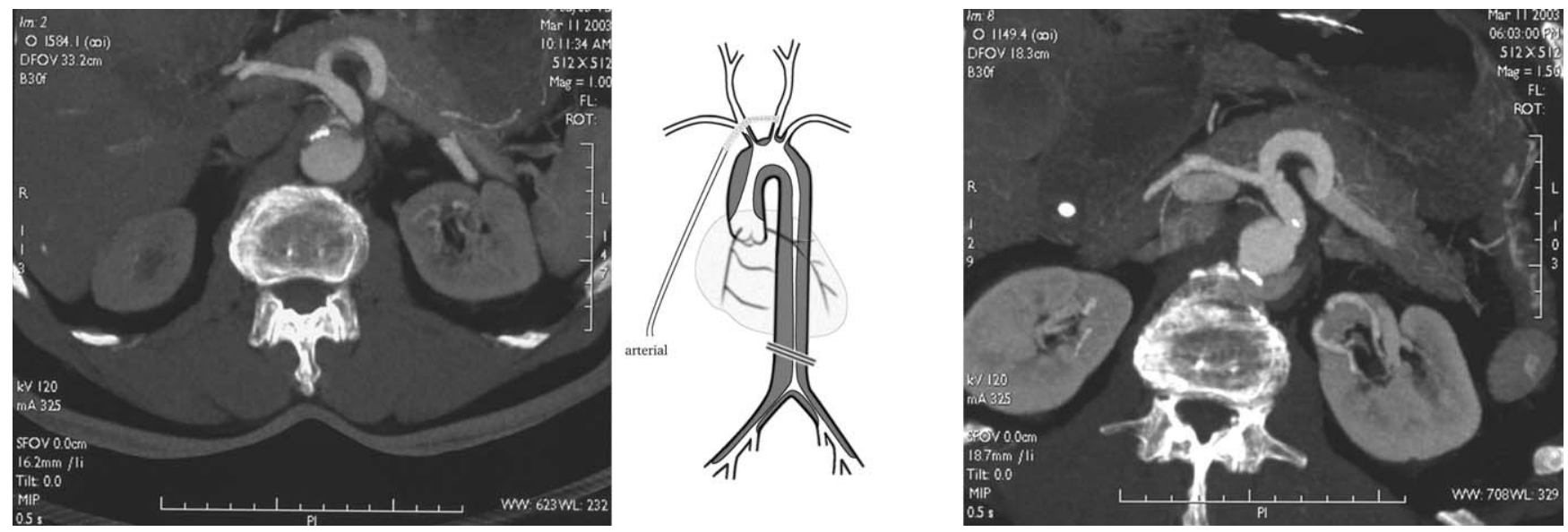

Figure 2. Left, Preoperative computed tomogram-angiograph showing aortic dissection with massive compression of the true lumen by the false lumen in the abdominal aorta and the resulting filiform stenosis of the celiac artery. Middle, Schematic illustration of aortic dissection and arterial return installation by means of cannulation of the left common carotid artery. Right, Postoperative computed tomogram-angiograph showing almost complete extension of the true lumen in the abdominal aorta with normal origin of the celiac artery.

We believe that the carotid arteries are an excellent site for arterial cannulation in acute aortic dissection, and we have established this method as a standard procedure in our clinic.

\section{References}

1. Reuthebuch O, Schurr U, Hellermann J, et al. Advantages of subclavian artery perfusion for repair of acute type A dissection. Eur J Cardiothorac Surg. 2004;26:592-8.
2. Neri E, Massetti M, Capannini G, et al. Axillary artery cannulation in type A aortic dissection operations. J Thorac Cardiovasc Surg. 1999; 118:324-9.

3. Fusco DS, Shaw RK, Tranqulli M, Kopf GS, Elefteriades JA. Femoral cannulation is safe for type A dissection repair. Ann Thorac Surg. 2004;78:1285-9.

4. Van Arsdell GS, David TE, Butany J. Autopsies in acute type A aortic dissection. Surgical implications. Circulation. 1998;98(suppl):II299-304.

5. Urbanski PP. Cannulation of the left common carotid artery for proximal aortic repair. J Thorac Cardiovasc Surg. 2003;126:887-8. 